Geopolítica(s) Revista de estudios sobre espacio y poder ISSN: 2172-3958

\title{
La geografía de las fronteras: El método ${ }^{1}$
}

\author{
Jacques Ancel
}

Publicado originalmente en 1936

Resumen. El texto es una primicia que el autor desarrollará posteriormente y se ilustra de estudios de caso y terminología original. Comienza con un breve aporte conceptual sobre la diferencia de planteamiento entre las escuelas geográficas alemana y francesa, y prosigue con una reflexión sobre la relatividad histórica y geográfica de la frontera. Después, en su mayor extensión, nos aporta una taxonomía u ordenación de Estados: los Estados amorfos, en tres supuestos, el de los "pueblos salvajes”, sin fronteras, del África negra; los pueblos semicivilizados del noroeste africano, y el caso particular de los nómadas civilizados europeos, los "terranovas". Los Estados encuadrados, fijándose en las fronteras en proceso de extensión o formación, en especial el caso de Yugoslavia, además de referencias a las fronteras estables de Albania y Países Bajos.

Palabras clave: Estado; frontera; geografía de fronteras; taxonomía de Estados; Yugoslavia.

\section{[en] The Geography of Borders: The Method}

\begin{abstract}
This text is a first that the author would develop later. It is illustrated with case studies and original terminology. It begins with a brief conceptual contribution on the difference in approach between the German and French geographical schools, and continues with a reflection on the historical and geographical relativity of the boundary. Subsequently, at its greatest extent, the article provides a taxonomy of states: amorphous states, in three cases, that of the "savage peoples" without boundaries, of black Africa; that of semi-civilized peoples of northwest Africa, and the particular case of European civilized nomads, called "terranovas". Framed states, with borders undergoing processes of emergence or extension, especially the case of Yugoslavia. And, in addition, some references to stable boundaries of Albania and the Netherlands.
\end{abstract}

Keywords: state; boundary; border geography; states taxonomy; Yugoslavia.

\section{[pt] A geografia das fronteiras: o método}

Resumo. O texto é o primeiro que o autor posteriormente desenvolvido e ilustrado por estudos de caso e terminologia originais. Ele inicia com uma breve contribuição conceitual sobre a diferença de abordagem entre a escola geográfica alemã e francesa, e continua com uma reflexão sobre a relatividade histórica e geográfica da fronteira. Então, em sua maior extensão, dá-nos uma taxonomia de estados: estados amorfos, em três casos, a dos "selvagens" sem fronteiras, África negra; os povos

1 (Nota de la redacción) Este texto corresponde al capítulo primero del Curso impartido por el autor en la Académie de Droit International y publicado con el título Les frontières. Étude de Géographie Politique, en Recueil des Cours, 1936. I, tome 55 de la Collection. París: Sirey, pp. 207-295. Traducido por Lorenzo López Trigal y Vicenta Fernández Rodero. Se ha respetado la literalidad del texto original, añadiendo en contadas ocasiones algún término [entre corchetes] para una mayor comprensión. 
semi-civilizados do noroeste da África, e o caso particular de nômades civilizados europeus, os "terranovas". Estados enquadrados, observando fronteiras no processo de extensão ou de formação, especialmente o caso da Jugoslávia, além de referências a fronteiras estáveis da Albânia e Holanda.

Palavras-chave: Estado; fronteira; geografia das fronteiras; taxonomia de Estados; Jugoslávia.

Sumario. 1. La noción de frontera. 2. Los Estados amorfos. 3. Los Estados encuadrados. 3.1. Fronteras en extensión. 3.2. Fronteras estables, recientes o antiguas.

Cómo citar: Ancel, Jacques (2016) “La geografía de las fronteras: El método”. Geopolítica(s). Revista de estudios sobre espacio y poder, vol. 7, núm. 1, 131-142.

\section{La noción de frontera}

La geografía de fronteras no es más que un aspecto de la geografía política, que se entiende en diversos sentidos. Según la escuela alemana [de geografía], la geografía política es exclusivamente la geografía de los grupos políticos o más exactamente la geografía de los Estados. Para la escuela alemana, surgida de la enseñanza de [Friedrich] Ratzel, el papel esencial que determina los Estados es atribuido al suelo. No hay necesidad de recordar aquí las dos concepciones capitales de Ratzel: la "posición” (Lage) y la "extensión” (Raum). De ello resulta una noción particular de frontera como la forma cartográfica del Estado: son sus movimientos los que marcan la grandeza o la decadencia de un Estado.

Ahora bien, la escuela francesa [de geografía] no adopta ni esta teoría ni este método. La escuela francesa, representada casi exclusivamente por la obra de [Paul] Vidal de la Blache, considera el hombre, según la expresión de su fundador, como un "factor geográfico": creador consciente de agrupaciones, que se satisface para adaptarse a los elementos naturales. Dicho de otro modo, la frontera no es más que un marco, provisional o permanente, en la actividad humana. Ella se modela sobre lo que se agita dentro, no sobre las facilidades o los obstáculos que encuentra para establecerse. Si, para emplear un término más simple, la frontera es un marco, como dice Lucien Febvre, lo que importa no es el marco sino lo que está enmarcado. Así, la geografía de fronteras es solamente la geografía de los límites impuestos a la actividad de un grupo. La frontera no puede estudiarse en sí misma, sino en relación a los grupos que ella separa. Ahora bien, estos grupos no son inmóviles. La frontera, pues, no está nunca determinada por la naturaleza sino por el hombre. Vive de acuerdo con los grupos [humanos], evoluciona con ellos, es función de un equilibrio. Precisamente, porque la frontera reposa sobre un equilibrio, la idea que los hombres se han hecho de la frontera ha evolucionado. Tomemos como ejemplos las concepciones antigua, medieval y moderna de la misma.

Relatividad histórica de la frontera.- El limes romano no era un límite. El Danubio era una línea de circulación interior, las ciudades romanas se edificaban sobre las dos orillas, la flota bizantina circulaba sobre el río a modo de una ruta de vigilancia imperial. Sobre la orilla izquierda, las cabezas de puente, defendidas por los limitanei, formaban aún partes Romaniae (Rumanía), opuestas al mundo bárbaro. El limes era construído — - levantado y excavado — en regiones desérticas: Siria, Áfica, 
y variaba según las necesidades de defensa; no fue nunca una línea regular, sino más bien una zona estratégica, elástica.

En la Edad Media, los bárbaros entran en el Imperio romano: así, los búlgaros en los Balcanes en el siglo VI. Las bandas encontraban allí ciudades organizadas. Los búlgaros, venidos de las estepas rusas, se instalaban en una zona poco habitable, se introducían en el ángulo que forman el Danubio y el Dniester, cerca de la Besarabia y la Dobrogea de hoy. Este país era sobre todo el camino de Constantinopla. Los soldados obedecen a sus khanes, simples jefes de bandas paganas que se hacen naturalizar cristianas a fin de permanecer en el Imperio, en la civilización europea. Ellas demandaban un tributo, una ciudad con comercio favorable, una plaza fuerte fronteriza donde se cambiaban productos: el medio práctico para obtener concesiones era pasarse a la ortodoxia. Así hizo el rey Boris al final del siglo IX. Desde entonces los búlgaros tratan de imitar a los otros cristianos; los jefes tratan de llegar a ser emperadores, césares (zares). El zar Simeón (893-927) tiene un Estado sin límites definidos: su dominio es hecho de concesiones imperiales, inscritas sobre los mojones que marcan los caminos de Constantinopla y de Salónica. Este imperio búlgaro dura poco: los pastores guardianes se alejan de su primer hábitat para emprender una razzia a uno y otro lado del valle. A veces triunfan, pero su éxito es a corto plazo. Tal fue el segundo Imperio búlgaro del siglo XI. Estos imperios no tienen fronteras sólidas: no son más que "dromocracias", potencias camineras.

En la época moderna prevalece la idea nacional, que no se precisa más que poco a poco en límites fijos. Serbia al comienzo del siglo XIX crece poco a poco hasta llegar a ser la Yugoslavia de hoy: sin embargo, no hubo nunca ideas claras y precisas sobre la frontera del Estado serbio. En 1878, con la anexión de Nis y de Pirot, se contiene de fragmentar las propiedades que atraviesan la frontera. En esta evolución aparecen a la vez un medio y un fin.

Una gran parte de la evolución humana está desarrollada en el trazado de las fronteras: la guerra, la diplomacia y otros factores estratégicos, económicos, morales han cooperado para diseñarlo. "El yo toma conciencia de sí mismo al contacto del no yo", ha dicho Vidal de la Blache hablando de Alsacia y Lorena. Es menos la frontera que se impone que la unidad nacional: la frontera se delimita siguiendo la evolución.

El fin perseguido es la relación entre los pueblos que tienen voluntades comunes, o la seguridad, bien defensa o bien protección, frente a pueblos diferentes. Esta seguridad, muy relativa, varía con el tiempo. De donde la tendencia hacia la seguridad ideal: la frontera denominada "natural" no es la frontera perfecta, concepto teórico, esperanza que no fue nunca realizada.

Dicho de otro modo, la voluntad humana es el elemento determinante. No hay "buena” o "mala” frontera: esto depende de las circunstancias. La frontera de los Pirineos es hoy una frontera muerta: la relación está en las tierras de habla francesa, por anexión de Navarra, del Rosellón. Antes, era una frontera de tensión: las gentes se batían. Después de que el peligro español desapareciera, acaba la hegemonía religiosa de la corte de España en 1598, su hegemonía territorial en 1648, el peligro es descartado, la frontera está muerta, no se presta más atención. Insisto sobre este punto: la voluntad del hombre fija la frontera. 
Relatividad geográfica de la frontera.- Es un grave error imaginarse que la naturaleza impone al hombre las fronteras mejor definidas, más estables que las que el hombre traza solo. La noción de "frontera natural” es una de las nociones favoritas y falsas más sólidamente ancladas entre los historiadores. En la práctica, no responde a nada relevante.

Los ríos fronterizos plantan a veces pulsos a los diplomáticos al no permanecer en su cauce. Ejemplos curiosos son suministrados por ríos de llanura de América del Sur. Entre ellos se perpetúan los litigios. Así entre Ecuador y Perú. Ecuador se ha instalado sobre la costa del Pacífico y, en origen, no desbordaba los Andes: sobre la vertiente oriental, Perú le disputaba las orillas del Marañón (alto Amazonas). En 1830, Perú establece sus puestos fronterizos sobre la orilla derecha y Ecuador las suyas sobre la orilla izquierda. Pero no se está de acuerdo sobre el curso del Marañón, río divagante: el curso de agua principal toma a menudo el lugar de un afluente, el río Negro a izquierda, el Javari a derecha. En 1916 es firmado un tratado de reparto de aguas; pero al Norte los ríos se burlan de los tratados y sus afluentes confunden sus aguas durante las crecidas. En 1922, Perú recula su frontera hacia el Norte, sobre la línea de reparto de aguas entre el río Negro y el río Putumayo. El asunto no está cerrado.

Otro ejemplo, más actual, lo muestra el conflicto del Chaco entre Bolivia y Paraguay (1932-1936). El Pilcomayo, afluente del Paraguay está, como todos los ríos del Chaco, dividido en varios brazos, que portan el nombre del río. El tratado de Buenos Aires (1876) que reparte el Chaco meridional entre Paraguay y Argentina, fija la frontera en el Pilcomayo inferior. La parte superior del río está dividida en dos tramos, formando una Mesopotamia [Entre Ríos] donde las aguas divagan. Este territorio fue sometido al arbitraje del Presidente de Estados Unidos que atribuye el Pilcomayo como frontera (1878). Pero, en 1904, Argentina coloca sus puestos fronterizos a lo largo del tramo Norte. La disputa se retoma en 1929 y no se ha solventado aún.

En las montañas, la famosa línea [de cumbres] “divisoria de aguas” no es menos disputada. Así ocurrió en los ríos de los Andes. Los ríos chilenos, que tienen su nivel de base bajo y próximo, son más activos: muerden sin cesar, reculando sus fuentes, sobre los ríos argentinos. La frontera teórica establece a menudo la "línea de crestas” sobre la línea de reparto de aguas, antaño confundidas sobre el terreno. Pero los ríos chilenos han sobrepasado la línea de crestas y la línea de reparto de aguas se ha encontrado rechazada sobre la vertiente oriental en detrimento de $\mathrm{Ar}$ gentina: es el origen de numerosas querellas que, hasta el presente, han permanecido acantonadas sobre el papel en notas diplomáticas.

Europa no está exenta de estos litigios, lo que provoca una geografía desconocida. Los tratados de Rapallo (1920) y de Roma (1924) han fijado la frontera italoyugoslava en la línea de reparto de aguas. Ahora bien, el karst de Istria, donde está trazada esta frontera, es un macizo calcáreo, cribado de sorpresas, atravesado de cavidades donde desaparecen los ríos. Después de un curso subterráneo más o menos largo, vuelven a la superficie en fuentes vauclisianas. También es absolutamente imposible determinar la línea de reparto de aguas, la frontera de agua entre los torrentes que desembocan en el Adriático y los ríos que descienden hacia el Sava, como el Ljubljanica. Muchas veces el curso de agua cambia de nombre. En la frontera Noreste de Istria, cerca de Postojna no se puede seguir el río que ha creado las 
célebres grutas de Adelsberg. Sobre toda esta zona fronteriza pueden surgir contestaciones, pretextos de conflicto.

No son solamente los hechos físicos los que provocan tales querellas históricas. Los hechos económicos, no menos maliciosos en nuestra época de cambios y trastornos rápidos, dan lugar a muchas controversias. Después de dieciséis años [de terminada la Gran Guerra], en Europa pululan los ejemplos. Tal la frontera entre Prusia Oriental y el "Corredor", más exactamente la [Pomerania] Pomorze polaca. Aquí, la frontera fue situada, no sobre el mismo Vístula, sino un poco más allá de la orilla derecha: no ha faltado vituperar la incomprensión de los redactores [del tratado] de Versalles. Sin embargo, el tratado no fue [ratificado] sin razones: la frontera fue establecida a lo largo del dique, que sigue la orilla derecha. El Vístula inunda periódicamente este bajo país en sus crecidas primaverales. Fue necesario conceder a Prusia el dique que protege sus tierras y que debe mantener, en Polonia el mismo curso del río, que es el gran eje de comunicaciones polacas e indispensable ligazón con Danzig y el mar.

La frontera del Dniester, entre Rumanía y Rusia, es otro ejemplo de las necesidades económicas que reparan los errores históricos seculares. Las dos orillas del Dniester como todos los ríos del Sur de Rusia, forman un impresionante contraste: frente a la orilla izquierda — hoy rusa — baja, inundable, la orilla derecha rumana - se dibuja como alto escarpe limoso. Los mismos sitios se reproducen al Oeste a lo largo del [río] Prut, que, de 1812 a 1918, sirve de frontera entre Moldavia, otomana, después libre, y Rusia que había arrebatado Besarabia o Moldavia oriental. En el siglo XIX, Rusia instaló en Besarabia colonias militares de todas las lenguas, alemanas en los campos, rusas en las ciudades. Sin embargo, la colonización agraria rumana, que desciende pacíficamente de la Montaña, era facilitada por la ocupación cómoda sobre la orilla izquierda, mientras que los emigrados del Este se topaban con la ruda escalada de la orilla derecha: también abordaba poco a poco la orilla izquierda del Prut, cercando las colonias militares de los conquistadores, sobrepasaba ella misma el Dniester, fijando a su vuelta los campesinos rumanos sobre la orilla izquierda del río. Después de la guerra, la frontera del Dniester, retomada por Rumanía, permanece disputada y cerrada durante dieciséis años. El tratado de no agresión rumano-soviético de 1933 reconoció de hecho la posesión de Besarabia por Rumanía. El tiempo solo se encarga de arreglar los litigios políticos surgidos de las nuevas dificultades económicas.

\section{Los Estados amorfos}

Pueblos salvajes del África negra.- Si la frontera no es más que una zona de equilibrio, cuya razón de ser puede encontrarse, no en el marco, sino en su interior, en la voluntad nacional, la geografía explicativa de las fronteras se reduce a la geografía de los Estados y de las Naciones. Pero ¿no hay Estados sin cohesión nacional, por consecuencia, sin fronteras? En la selva virgen africana no hay apenas otro Estado que el grupo molecular, la primitiva aldea. He aquí un lugar sobre un alto talud que la inundación no amenaza: la aldea del Ogooué, en el Oubanghi, se sitúa, protegida en su cerro por el suelo deslizante, la pendiente escarpada, la espesura vegetal, los fosos, las trampas, los árboles derribados. Desde que el hombre fortifica lo que le 
ofrece la naturaleza se está en presencia de una frontera. Es un Estado miniatura este pueblo fang, descrito por el gobernador Cureau en medio de la selva virgen. Subsiste de sus propios productos, bananas y patatas, habas y pimientos. Los hombres deben asociarse para abatir los gigantes de la selva y para establecer claros [bosque-galería]. Deben agruparse aún para sorprender a los antílopes, los búfalos, los elefantes. Es preciso, para vivir, una base de disciplina, una cohesión de esfuerzos, la constitución de un Estado, un esbozo de monarquía, el tata, jefe del pueblo. $\mathrm{Y}$ desde que el Estado se forma, es preciso defenderse contra las incursiones de los vecinos. De otro lado, el Estado es nómada: debe desplazarse en búsqueda de alimento, desbrozar mediante el fuego el bosque hostil, crear de lugar en lugar un nuevo claro y un nuevo sitio. La frontera es allí móvil.

[Pueblos] semicivilizados del África blanca. En las estepas del Norte de África, los límites de los Estados no están fijados. Desde 1845, el tratado de Lalla-Marnia —el primer tratado entre Francia y Marruecos que entraba en Argelia - indica muy bien las dificultades del amojonamiento: "No hay límite territorial establecido entre los dos países, ya que la tierra no se cultiva y sirve de pastoreo solamente a los árabes de los dos Imperios que vienen a acampar para encontrar los pastos y el agua”. En las estepas, en efecto, el nomadismo prima sobre todo. El Estado pastoril es un Estado que se traslada. La frontera es elástica, a lo largo de las rutas de su recorrido. Los Lârba nomadean en las altas mesetas del Sahara al Tell, de las dayas a Tiaret. Los Angad del Oranesado están en el invierno alrededor del chott El Gharbi, en primavera sobre las estepas del Dhara, donde las tormentas hacen crecer nuevos manojos de esparto o de artemisa, en verano en el Atlas. En la Tunisia del Tell, la mayoría de las tribus montañesas poseen una parte de llanura adyacente; las poblaciones de las lindes detentan una porción de estepa y de Tell, que sirven alternativamente para el estío y para el invierno. Incluso los más sedentarios del alto Tell experimentan la necesidad de "otoñar entre los cactus”, según la expresión árabe, es decir, van a recolectar en la estepa las raquetas jugosas de los higos de Barbaria [higos chumbos], que dan a sus corderos o a sus bueyes. La horda está en movimiento según las estaciones. La noción de frontera es incompatible con la naturaleza física y con la vida social.

Del mismo modo, las poblaciones del Medio Atlas están en perpetua mudanza: no viven más que durante el verano en los pastos de montaña, por encima de 2.500 metros, más allá de los bosques de cedros. En el invierno descienden hacia el océano. Los Beni M'guild poseen varios dominios: sitúan en los valles altos de la Mouloudia y del Sebú sus graneros fortificados o tirremt; explotan la madera, el carbón de leña de las pendientes; pastorean sus rebaños en los pastos alpestres. El nomadismo toma a veces un aspecto belicoso de las razzias periódicas y los Bereber pasaron mucho tiempo como los pueblos más salvajes de Marruecos: era, para los sultanes de antaño, el "país de la revuelta", Blad es Siva, opuesto al "país de la sumisión”, Blad es Maghsen, el "reducto de la resistencia bereber" (Augustin Bernard). A la inversa, cuando el sultán quería "alimentarse de una tribu”, enviaba sus soldados a descubrir los escondrijos donde se ocultaban las cosechas. ¿Dónde estaba la frontera de su Imperio, en las lindes de las llanuras sometidas o más allá de la Montaña rebelde? Ha sido necesaria la "paz francesa" para juntar los dos dominios y enseñar a los indígenas lo que se entiende por "frontera”. 
Nómadas civilizados europeos en América.- Vayamos aún más lejos. ¿Dónde está la frontera en una isla de pescadores? No está seguramente en el litoral, ya que el mar que abastece y provisiona es un hábitat temporal y el verdadero "campo". El mar da a menudo al hombre lo que la tierra le rehúsa. Alrededor de Terranova, viejo suelo limado por los glaciares, en las costas marmóreas escarpadas o roídas en panes de azúcar, en columnas, en ondulaciones graníticas, es el mar que atrae al hombre: su fauna litoral del bogavante, lenguado, rodaballo, y, más allá, los bancos de arenque, bacalao, promocionan la pesca, que atrae una inmensa población flotante; los "terranovas" de Bretaña, del País Vasco, de Portugal, de Nueva Inglaterra, encuentran en estos parajes una segunda patria. Europa no es para ellos más que un [lugar de] veraneo. Aquí está su verdadero dominio. La casa es la goleta y sus doris, barcos sin quilla. La pobre cabaña de Saint-John's o de Saint-Pierre, simple chalet de invierno, apelotonado contra el viento, contra el frío, ¿puede compararse a la fortaleza flotante de tres mástiles donde habita o donde trabaja seis meses, de marzo a octubre? Terranova no fue nunca una colonia. Es el mar el que es un vivero: la isla no existe más que por él. Cuando Inglaterra generosa le ofreció ser un Dominio, no aceptó la experiencia de la independencia que nunca solicitó. Hoy, Terranova ha rechazado sus límites y ha querido, a través del mar, ser simple “colonia” inglesa, ligarse más tiempo a la metrópoli.

\section{Los Estados encuadrados}

El principio nacional está en la base de la civilización europea. Ella, [la Nación], es la que crea los Estados contemporáneos, no la naturaleza. Es el caso de los nuevos Estados balcánicos.

La montaña, célula de Estado.- La península balcánica parece nacida para la fragmentación. Puede definirse por su mismo nombre: la palabra turca Balkan quiere decir “Montaña”. De cualquier lado que se aborde, se topa con la Montaña. El mar Egeo es dominado por la roca, blanca o gris, generalmente pelada. Al Sur de Albania, en el litoral que los antiguos han llamado "Quimera", la Himara dibuja grandes rayas centelleantes y calvas. Y este rincón albanés se repite en numerosos ejemplos a lo largo de la costa adriática, hasta los cabos de Istria. Cuando el Simplon-Orient Express ha franqueado las vastas y monótonas llanuras del Sava, pasado Belgrado, las cimas redondeadas y boscosas marcan el comienzo de los Balcanes, la Šmadija, el país del "bosque" serbio.

Así, desde que se accede a la península, uno está sorprendido por el aspecto montañoso. Al Sur, tras el Egeo, es el comienzo del mar sin islas del Mediterráneo oriental, que contrasta con el archipiélago, sembrado de roquedo desnudo. Al Noreste, detrás de las colinas redondeadas que los rumanos llaman Codri, se descubre la gran estepa, la llanura monótona de Rusia. Detrás de las paredes blancas del Adriático, detrás de las Planine, se extienden las grandes llanuras de Europa central, comenzando por la Puszta magiar. Hacia el Noroeste, más allá del karst, de las secas mesetas calcáreas de Albania a Istria, más allá de la Soĉa, se despliega la llanura padana. Todo alrededor, vastos horizontes. [Mientras que] el rasgo propio 
de la península Balcánica viene, al contrario, de sus horizontes limitados, cadenas plegadas del Oeste, macizos ondulados del Este, cortados por profundas fosas.

La Montaña es pues el elemento primordial del paisaje balcánico. Sin hablar de su papel histórico - fue el conservatorio de las libertades balcánicas en épocas heroicas, el rompeolas de las guerras de independencia durante un siglo, 18041913-, ha impuesto su disciplina social, el particularismo de las tribus y de los clanes, su disciplina económica, la vida pastoril y trashumante. Las llanuras interiores balcánicas no son más que piemontes, que participan de la vida montañesa: tales como la Valaquia, la Moldavia, rumanas, las pequeñas llanuras incluidas en Albania y Grecia, las cuencas interiores de Macedonia y la vieja Serbia.

Ahora bien, desde hace dieciséis años [1920], el papel ancestral de la Montaña se ha transformado y ya no juega su papel tradicional de ciudadela:

1. La creación de Estados nacionales, comprendido Turquía, que sustituyen a los Imperios monstruo autrohúngaro u otomano ha complicado la frontera. Los Estados, aún poco estables, han tenido tendencia a encerrarse, a cerrar sus caminos al nomadismo. Bueyes de la zona verde septentrional, ovejas de la zona blanca del Sur, no pueden apenas, retomando la pintoresca expresión del historiador rumano Iorga, pasar de su "patria de verano" (los alpages del Norte) a su "patria de invierno" (los campos del litoral, Câmp de Valaquia o Besarabia, Campania de Salónica, Tesalia, llanura albanesa). El cierre de los caminos fuerza al campesino a modificar su economía rural.

2. Estos Estados nacionales son todos Estados rurales. Los campesinos fueron los soldados de las guerras de independencia. Las propiedades pertenecían a los súbditos de los países vencidos, beg musulmanes, magnates húngaros, grandes señores de Rusia o de Austria. Los tratados de 1919-1920 fueron seguidos de reformas agrarias, de reparto de los grandes dominios. Estos latifundios estaban en la Llanura, en la linde de los Estados: bocages rumanos (de una parte y otra de los Cárpatos), "mesopotamias” serbia y croata (entre el Sava y el Drava), campagnes griegas, pantanosas y malsanas (al pie de las costas de Tracia, de Macedonia, de Tesalia), en fin, cuencas cerradas del interior de los Balcanes. Antes, el movimiento nacional surgía de la Montaña, "país de la revuelta”, como en Marruecos; la Llanura era el "país de la sumisión". Hoy, unido estrechamente al terreno, el campesino de la llanura demanda al Estado sostener su nueva economía. El cultivador de trigo quiere vender. La sobriedad balcánica no absorbe la cosecha: el nivel de vida es aún muy bajo. La pequeña propiedad balcánica —a pesar de la ayuda de las cooperativas - permanece fragmentada, ligada a los viejos tipos de cultivo manual, a las viejas pistas, caminos insuficientes, a los enormes gastos de una explotación poco racional.

3. El nacionalismo lingüístico — rasgo general de la Europa de posguerraha provocado la agrupación en los Estados nacionales de la misma lengua. La mezcla de pueblos, migraciones más o menos voluntarias, es el rasgo tópico de la vida balcánica entre 1920 y 1930. A la par de la convención turco-griega de enero de 1923, que precedió al tratado de Lausana, 1.221.000 griegos dejaron Asia menor, Tracia oriental, para instalarse alre- 
dedor de Atenas, en Tesalia, en Tracia occidental y sobre todo en Macedonia meridional. De otra parte, se quiera o no, 133.000 macedonios, que se sentían búlgaros, abandonaron Macedonia occidental para alcanzar Macedonia oriental (búlgara), e incluso las llanuras de Bulgaria oriental, entre otras la de Burgas. En fin, para poblar las tierras desiertas del Sur de Serbia (Vieja Serbia y Macedonia del Norte), el gobierno yugoslavo instaló más de 100.000 colonos, venidos de las tierras caras de la Vojvodina (al norte de Belgrado), hacia las tierras baratas de Dalmacia y Macedonia.

Así, al mismo tiempo que la Nación tiene aceptación en todos sus dominios, político, social, lingüístico, el marco que la contenía cambia de razón de ser: la frontera es móvil, deslizante, no solamente en el mapa, sino en su esencia. Así se extienden algunos Estados, mientras que otros se encogen. Entre ellos, Yugoslavia, que fragua sus fronteras al tiempo que la Nación toma conciencia. Cuando la Nación se concentra en un Estado, sus fronteras tienden a estabilizarse.

\subsection{Fronteras en extensión}

La Nación Yugoslava.- Yugoslavia es un país mixto. El mapa muestra con evidencia que Yugoslavia se estira hacia Europa central por la gran arteria del Danubio. Tiende también hacia Europa mediterránea por las influencias que le rodean, de dos lados a la vez, al Sur y sobre el Adriático mismo, bordeado por una franja mediterránea. Dos influencias se enfrentan, continental y marítima.

Las lluvias de verano de Europa continental determinan una "zona verde", opuesta a la "zona blanca", el país de los setos, de los bosques en las montañas, los bocages en la llanuras, los pastizales en las mesopotamias del Drava y del Sava. Allí se ha constituido una civilización rural, tanto agrícola como ganadera, que se concentra siempre en la aldea.

De otro lado, se insinúan las influencias mediterráneas: la sequía estival crea la "zona blanca”. La montaña calcárea del Adriático, la gran sequía de los veranos, las lluvias débiles de los inviernos, determinan otro paisaje que permiten influencias marítimas y urbanas: la vida del litoral penetra en el interior; la civilización mediterránea estuvo siempre concentrada en los pueblos y villas desde la antigüedad. Tales son los elementos creadores de la Nación yugoslava.

Se agranda por una evolución que no le es ajena. La idea nacional es lanzada, como en todos los países balcánicos en el siglo XIX, por un Renacimiento intelectual, que crea la pequeña Serbia, pero que tiene su origen fuera de los Balcanes. Novisad fue el hogar intelectual en el siglo XVIII. De Karlovci, en la misma época, salen los sacerdotes propagandistas, iniciadores de la emancipación yugoslava. Posteriormente, un Renacimiento territorial, balcánico, parte de la Montaña, ciudadela de las resistencias, conservatorio de las libertades: Balcán para los búlgaros, cadenas del centro rumelio para los griegos, macizos del Norte, Sumadija y Bosnia para los serbios, Cárpatos para los rumanos. En la Montaña surgirán las legendarias hajduci, repetidas en los cantos heroicos yugoslavos, los momci, de los primeros combatientes por la independencia de Serbia.

En el siglo XX, un tercer Renacimiento social surge de la contraposición entre la civilización continental y la civilización mediterránea. En estos dos hogares se 
alumbraron concepciones políticas. Mientras que en la civilización continental, esencialmente campesina, la reacción de los rurales - los agrarios - fue más viva, en el mundo urbano, mediterráneo, se impuso una tradición administrativa, política: el estado mayor ciudadano había decidido la independencia y establecido las bases de la administración contemporánea, que pretendía guardar siempre el dominio de ciudades y campos.

Este contraste entre la civilización urbana y la civilización rural fue relegada a un segundo plano en el siglo XIX, época de luchas heroicas. Desde la separación de Austria-Hungría, las masas campesinas, habituadas a otro tipo de agricultura, en el horizonte más amplio de las mesopotamias del Norte, a una vieja política occidental, entraron en contacto con la administración urbana, bizantina, del gospodin, "señor". El conflicto estalla: el campesino que se apodera de la tierra codicia también el poder. Este Renacimiento social, engendrado por un estado de espíritu campesino, que nace en el siglo XX, resiste a la oligarquía de los señores de la ciudad:

1. Primera Etapa: Células Originales. Este contraste explica aún, en gran parte, la formación del Estado. Las células constitutivas del primer Estado serbio, las “comarcas” (župe) han mostrado durante tiempo una vida en reclusión. Casi toda Yugoslavia está formada de estas pequeñas células, encerradas en un marco montañoso. En la región calcárea adriática, en las llanuras de hundimiento de la Vieja Serbia y Macedonia, en los polja y sus piedemontes cercados por la Montaña, se encierran tribus antiguas, los plemena de Montenegro. El pleme vive replegado en sí mismo: con sus corderos, cambia de patria según el verano y según el invierno, apenas tiene necesidades externas, relaciones con los demás. Así, la župa aislada, la Stari Vlah, la Vieja Valaquia. A 1.200-1.300 metros de altitud, las relaciones con los vecinos no son fáciles. Estos viejos serbios han vivido durante tiempo de sus rebaños de ovejas. Al Sur, una župa abierta, el Kosovo, a 500 metros de altitud, con relaciones más fáciles con los otros polja de la Vieja Serbia, como Metohija al Oeste, el valle del Morava al Noreste, Macedonia al Sureste, por el desfiladero de Kacanik, de donde se desciende al Vardar, a Skoplje. Otra célula, el microestado que fue largo tiempo Montenegro, reúne las pequeñas cuencas (vala), pequeñas tribus (plemena) dominadas por los kula, fortificaciones muy simples de piedra por encima de este paisaje rocoso. El esfuerzo de Montenegro fue, en los siglos XVIII y XIX, conquistar lo que le faltaba: las montañas de esquisto y herbosas, los Brda, praderas que contrastan con el Montenegro calcáreo; la llanura, casi exclusivamente del lago de Scutari; en fin, la salida al mar. Obtenido este acceso, Montenegro se funde en el conjunto de las comarcas serbias.

2. Segunda Etapa: Relaciones. El Estado serbio se ha formado uniendo estas células sobre rutas fijas, en particular sobre el eje del Morava superior, después de la confluencia del Vardar. La geografía de estos dos valles contrapuestos explica el Estado yugoslavo: alternancia de gargantas estrechas y de amplias cuencas, se unen a través de umbrales de paso fácil, de Presevo, de Kumanovo. De un lado y otro, no se percibe apenas la subida ni el descenso; los riachuelos que circulan hacia el Morava, hacia el Vardar, no tienen claro su camino: según las lluvias y las estaciones, las aguas circu- 
lan tanto hacia el Norte como hacia el Sur. El eje de este doble valle es la arteria vital del Estado serbio. En 1815 se funde la pequeña Serbia independiente en los límites del pachalik de Belgrado. En 1833 adquiere los "seis distritos" del Sur en la ruta del Morava. En 1878, en el tratado de Berlin, alcanza Nis y Pirot. Al fin, en 1912, después de la primera guerra balcánica, se extiende sobre el Vardar, obtiene Skoplje, reparte Macedonia con Grecia y Bulgaria (tratado de Bucarest, 1913). Deslizamiento sobre el Vardar, pero también atracción hacia el Sur, hasta la ciudad "codiciada” de Salónica.

\subsection{Fronteras estables, recientes 0 antiguas}

Albania.- Es una excepción entre los países balcánicos. Los otros pueblos han formado primero pequeños Estados, después se han aglutinado en Naciones densas; a la inversa, Albania [como] Nación, surge fuera de sus límites territoriales, entre los albaneses emigrados a América, filántropos y patriotas, fundadores, después de conseguida una fortuna, de escuelas en sus poblaciones natales. La lengua albanesa era el único intermediario de una civilización múltiple. Sin tener en cuenta los tratados que habían trazado las fronteras en 1913 y 1920, no se circunscribía en un Estado. Rechazada en un nuevo marco por la desaparición de la Turquía europea, por la fundación de Estados excéntricos con bases nacionales, Yugoslavia y Grecia, Albania adopta, en contraste, un papel político que no había obtenido en el pasado.

Tres zonas físicas se reparten Albania, correspondientes a tres civilizaciones diferentes. Al Norte, estrechos valles, obstruidos entre barreras calcáreas, abruptas, donde las tribus (fiss) llevan una vida patriarcal. Al Sur, amplios valles extensos de cuencas fértiles, rutas naturales ligadas a Grecia y al mar, donde en ciudades mercantiles se ha establecido una burguesía de negocios en Korça y en Saranda. En el Centro, las llanuras, a menudo estériles, palúdicas, donde se extienden las grandes propiedades de los beg. Estas tres regiones responden a las divisiones religiosas clásicas: católica, ortodoxa, musulmana (aunque no conviene ciertamente exagerar su importancia, cuando la religión no sirve para obtener apoyo extranjero). Salvo al Norte, donde la elevada muralla de los [montes] Prokletije dibuja una sólida frontera, nada impone límites: los ríos albaneses nacen en Yugoslavia o Grecia y las barreras montañosas [dirección] Norte-Sur se reproducen en ejemplares múltiples en Macedonia como en Albania; las tribus y los rebaños nómadas no se preocupan por nada. Faltaba, de otro lado, en la Nación, el elemento constitutivo de la unidad, la ruta. Los italianos la aportan, haciendo así de la Nación albanesa un Estado albanés, aunque un Estado vasallo. Después de los dos tratados protectores de Tirana (1926-1927), seis rutas fueron trazadas desde el mar a las fronteras, reposición de pistas antiguas o construcción de vías nuevas.

La incertidumbre de las fronteras es debida aquí a la duda de la Nación. En la actualidad, la Nación se elabora por la fusión de tres células, y se fortifica en el interior, frente a los vecinos, en una frontera que no imponía la naturaleza, sino que se fija por la cohesión y la conciencia nacionales.

El ejemplo de Albania es tópico de una frontera que se estabiliza. Los protocolos, los tratados que han creado Albania, no han trazado más que en el papel los límites. De hecho, la frontera no se precisa más que en el momento donde la nacio- 
nalidad albanesa encuentra, por la trabazón de rutas y la mezcla de sus pueblos, su unidad. A partir de este momento reciente, ningún fenómeno físico cuenta más: el relieve, que se repite a intervalos regulares, no justifica las bornas fronterizas montañosas; los valles, que descienden de los países vecinos, no sirven más que de pretextos a las ambiciones rivales; la lengua, que rebasa los espacios administrativos, no beneficia nada, para definirse, de otras tierras irredentas. Como por encanto, el límite territorial se precisa cuando se libera el alma del interior.

Países Bajos.- En oposición a Europa, las fronteras de los Países Bajos fueron notablemente estables desde el siglo XVI. Cuando la Nación holandesa toma conciencia ella misma contra la Potencia católica española, cuando creó, entre las civilizaciones de lengua germánica, una civilización original, se planteó, por primera vez, frente al Imperio, la cuestión de sus fronteras. En el Este, a lo largo de una amplia zona de turberas, durante tiempo despobladas, la frontera es inmutable. $\mathrm{Al}$ Sur, al contrario, las zonas geográficas se prolongan, Provincias Unidas de los Países Bajos españoles, el gran arenal, después la zona baja de los polders. Ninguna causa física podía, en estos lugares, determinar una frontera. El nuevo Estado "se paraba en los mismos límites de la ley protestante” (Albert Demangeon): el protestantismo había levantado el estandarte de la revuelta, había fundado un alma nacional. Aquí, solamente, el fermento moral hacía surgir una frontera.

Esto es tanto como decir, en conclusión, que no se considera un problema de fronteras lo que no es más que un problema de Naciones. 